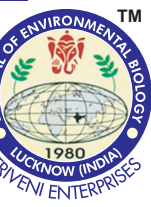

\title{
QTL mapping for morphological and physiological traits in RILs of spring wheat population of WH1021 $\times$ WH711
}

\begin{tabular}{llll}
\hline Paper received: 12.09 .2018 & Revised received: 09.01.2019 & Re-revised received: 28.01.2019 & Accepted: 11.02 .2019 \\
\hline
\end{tabular}

\begin{abstract}
Authors Info
S. Sangwan ${ }^{1}$, R. Munjal',

K. Ram ${ }^{1}$ and N. Kumar ${ }^{2 *}$

${ }^{1}$ Department of Botany and Plant Physiology, Chaudhary Charan Singh Haryana Agricultural University, Hisar-125 001, India

${ }^{2}$ Wheat \& Barley section, Department of Genetics \& Plant Breeding, Chaudhary Charan Singh Haryana Agricultural University, Hisar-125 001, India

*Corresponding Author Email : nimbhal@gmail.com
\end{abstract}

\section{Edited by \\ Dr. A. Hemantaranjan}

Reviewed by

Dr. Surendra Singh

Dr. Sumati Gaumat

\section{Abstract}

Aim : To identify the quantitative trait loci (QTLs) associated with various morphological and physiological traits.

Methodology : A recombinant inbred line (RIL) population of wheat (Triticum aestivum L.) derived from cross of heat tolerant parent WH1021 with heat sensitive parent WH711 was used. For creation of heat stress delay in sowing (four weeks) was done in late sown from timely sown. Days to heading, days to maturity, plant height along with physiological traits viz. photosynthetic rate, transpiration rate, intrinsic water use efficiency (iWUE) and normalized difference vegetative index (NDVI) were recorded in both timely and late sown conditions over two years.

Results : A linkage map consisting of 22 SSR was prepared covering eleven chromosome of wheat. Using the software WinQTL cartographer version 2.5, significant genomic regions associated with heat tolerance were observed on $2 \mathrm{~A}, 2 \mathrm{D}, 4 \mathrm{~A}$ and $5 \mathrm{~A}$ chromosomes with composite interval mapping. QTLs for photosynthetic rate were found consistently for both years on chromosome 2D. In present study, significant variation was reported for days to heading and its QTLs were identified on chromosome $2 \mathrm{~A}$ and $2 \mathrm{D}$.

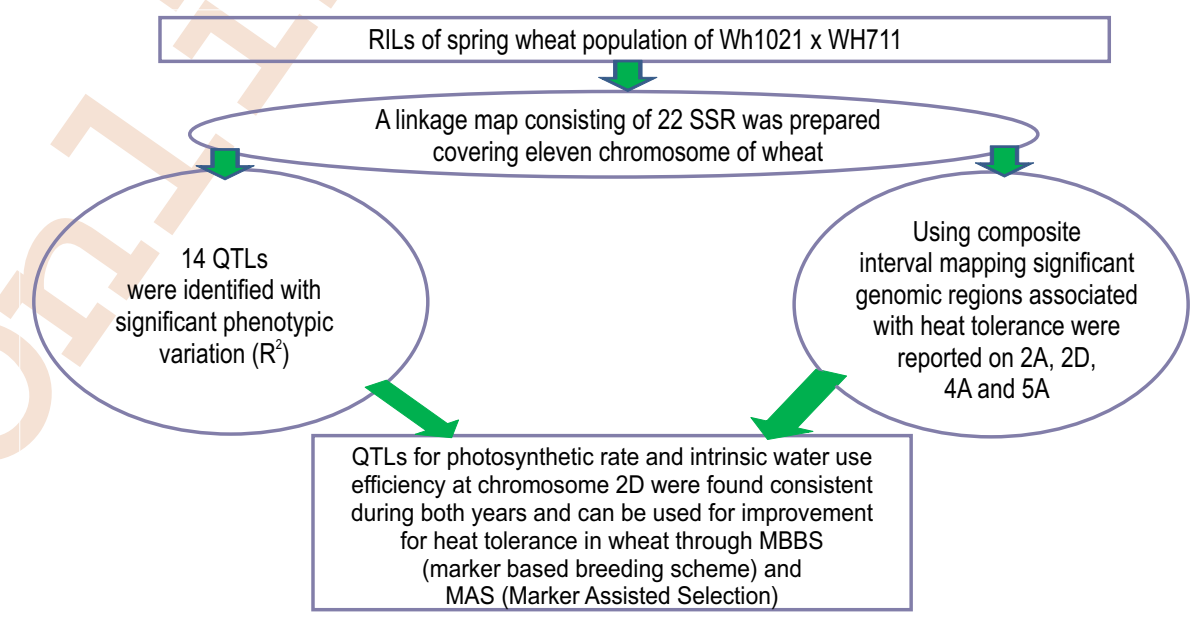

Interpretation : The QTLs obtained for physiological and morphological traits in wheat can be used for marker-assisted selection for heat tolerance in wheat.

Key words: Heat tolerance, Linkage map, Normalized vegetation index, Photosynthetic rate, Recombinant inbred line

How to cite : Sangwan, S., R. Munjal, K. Ram and N. Kumar : QTL mapping for morphological and physiological traits in RILs of spring wheat population of WH1021 × WH711. J. Environ. Biol., 40, 674-682 (2019). 


\section{Introduction}

Wheat, a chief benefactor to human health and nutrition (Shewry and Hey, 2015), is a cool season crop. However, in many regions of world, wheat faces heat stress at reproductive stage prominently (Barnabas et al., 2008; Sunita et al., 2017). Heat stress causes reduction in wheat yield by accelerating growth, shorten the phasic development stages duration and net assimilation reduction due to carbon starvation (Blum, 1988; Hall, 1992; Shpiler and Blum, 1991; Ram et al., 2017). In temperate environment $40 \%$ falls in yield occurs under heat stress which extends over 36 million ha (Reynolds et al., 2001). Heat stress affected the large portion of South Asia wheat growing region, of which significant portion is present in India (Joshi et al., 2007a). During grain filling high temperature above optimum causes $3-4 \%$ reduction in yield per $1^{\circ} \mathrm{C}$ rise (Wardlaw et al., 1989). In India, heat stress covers more than 13.5 million ha of wheat growing area (Joshi et al., 2007c). Two major causes of vulnerability of wheat to high temperature in India and neighboring countries are location near to equator and wheat and rice cropping system, causes the delay in wheat sowing (Rane et al., 2007). In India, decreasing of 'cool period' for wheat crop made it to face terminal higher temperature for longer duration (Rane et al., 2007; Joshi et al., 2007a).

Wheat germplasm has significant variation for heat tolerance (Reynolds et al., 1994; Joshi et al., 2007b and 2007c). So there is an urgent need to identify the traits and gene associated with tolerance to high temperature for developing wheat varieties, which are adapted to high temperature for fulfillment of the food demand to the increasing population with diminishing agricultural, land (Ortiz et al., 2008; Reynolds et al., 2007). Heat tolerance is a quantitative trait, which is controlled by number of genes or quantitative trait loci, those are involved in interaction with each other or environment (Blum, 1988). Availability of molecular markers along with improved and powerful statistical methods facilitates the QTL mapping. QTLs for heat tolerance were explored using different physiological traits and yield related traits (Yang et al., 2002; Mason et al., 2010; Pinto et al., 2010; Vijayalakshmi et al., 2010). Pinto et al. (2010) and Bennett et al. (2012) reported the effect of heat and drought stress separately on mapping population in controlled field conditions. Pinto et al. (2010) identified the common QTL for both heat and drought tolerance on chromosome 1B, 2B, 3B, 4A, 4B, $7 A$ and found association of these QTLs with agronomic and physiological traits like grain number, thousand grains weight, canopy temperature and chlorophyll content. Bennett et al. (2012) also reported two major QTLs associated with yield and physiological traits on chromosome $3 \mathrm{~B}$.

Balota et al. (2008) also reported associations of QTLS with different physiological traits. Development of molecular marker technologies and QTL mapping has revolutionized the genetic analysis of crop plants and made it possible to dissect complex physiological traits such as heat stress. The conventional breeders, physiologists and molecular biologists should exploit the knowledge gained through advances made in QTL analysis and molecular marker technologies through marker-assisted selection. Keeping in view the above facts, the present investigation was undertaken with the objective to map QTL for morphological and physiological traits associated with heat tolerance.

\section{Materials and Methods}

Plant materials and field evaluation: Plant material consisted a mapping population of 80 recombinant inbred lines (RILs) derived by crossing WH1021 with WH711. WH1021 is a heat tolerant variety recommended for late sowing whereas WH711 is heat susceptible, however of agronomical advantage. RILs population along with parental varieties were grown at Wheat Research Farm Area, Department of Genetics \& Plant Breeding, CCS HAU, Hisar, India, in 2015-16 and 2016-17 crop seasons. For creating heat stress at reproductive stage, RILs grown under two environments - timely sown and late sown. RILs population along with parental varieties during rabi season of 2015-16 were grown on November 20 and December 22 using augmented design under timely and late sown conditions, respectively.

During rabi season 2016-17, the crop was grown on November 14 and December 16 using randomized block design with three replications under timely and late sown conditions, respectively. Plots consisted of two rows of $1 \mathrm{~m}$ length with a $23 \times 10$ $\mathrm{cm}$ spacing between rows and plants. Both timely sown and late sown experiments conducted were under irrigated conditions and provided with recommended dose of fertilizers. Recommended dose of propiconzole 25\% EC (broad spectrum systemic fungicide) was used to eliminate the effect of fungal pathogens on yield of plants. Weather data during crop duration for both years were obtained from Department of Meteorology, CCS HAU, Hisar.

Phenotypic traits measurement: Samples from each plot were collected prior to complete harvest for estimating of yield components. Yield components, i.e., biological yield/plant and grain yield/plant were observed by randomly selecting five plants from each plot. Spikelets/spike, spike length, grains weight/spike and grains number/spike were estimated by harvesting ten spikes from each plot. Weight of hundred grains was recorded by counting 100 grains and weighing them on electronic balance. Plant height was measured from soil surface to the tip of spike excluding awns. Days to heading was observed as number of days from date of sowing until $75 \%$ heading was observed in plot. Days to maturity, indicated by yellowing of peduncle was measured as timing from planting up to senescence of inflorescence. Photosynthetic rate $(\mathrm{Pn})$ and transpiration rate (E) of flag leaf were measured with infra red gas analyzer (IRGA, LCi-SD, ADC biosciences) at anthesis and 10 days after anthesis. Intrinsic water use efficiency was calculated from photosynthetic rate/stomatal conductance. Normalized Difference Vegetative Index (NDVI) was also recorded at anthesis and 10 days after anthesis by using Green Seeker Instrument based on spectral reflectance. 
Genotyping using SSR markers: Genomic DNA of parental genotypes and RILs were isolated using CTAB method of SaghaiMaroof et al. (1984). Quantity and quality of genomic DNA were tested on $0.8 \%$ agarose gel by using standard DNA ladder. A total of 100 markers widely distributed over different chromosomes of wheat were used in this study. Amplification of genomic DNA of parental genotypes and RILs was done with 'BIO RAD T100" Thermal Cycler' using following conditions: Initial denaturation $94^{\circ} \mathrm{C}$ for $4 \mathrm{~min}$, Denaturation $-94^{\circ} \mathrm{C}$ for $1 \mathrm{~min}$, Annealing $-50^{\circ} \mathrm{C}$ to $60^{\circ} \mathrm{C}$ (vary with SSR primers used) for $1 \mathrm{~min}$, Extension $-72^{\circ} \mathrm{C}$ for $1 \mathrm{~min}, 35$ cycles from denaturation to extension step, Final extension $-72^{\circ} \mathrm{C}$ for $10 \mathrm{~min}$. PCR products were resolved by using 2.5\% horizontal agarose gel electrophoresis and for better resolution these amplification products were resolved on $6 \%$ polyacrylamide gel electrophoresis using CBS Mega-Gel System (High Throughput Vertical) as described by Wang et al. (2003). Profiles of polymorphic SSR markers were scored visually by coding 2 and 0 for the bands specific to tolerant and sensitive parent respectively, as 2- homozygous tolerant, 0- homozygous sensitive, 1- heterozygous and -1 for missing, for each RIL.

Statistical and QTL analysis: Analysis of variance and Pearson's correlation of phenotypic traits were done by using
OPSTAT software available on CCS HAU, Hisar, (www. hau. ernet. in) by Sheoran et al. (1998). Single marker analysis and composite interval mapping was done by using WinQTL Cartographer version-2.5. Initially single marker analysis (SMA) was done to find out association between polymorphic SSR markers and phenotypic traits. For determining the likely QTL position, composite interval mapping (CIM) was used.

\section{Results and Discussion}

Phenotyping: Mean and range of various morphological and physiological traits of parents along with RILs population are presented in Table 1. There was less percent reduction in yield components of WH1021 (heat tolerant parent) as compared to WH711 (heat susceptible parent) during late sown conditions. Grain yield/plant of tolerant parent was $11.36 \pm 0.04$ and $8.90 \pm 0.02$ during timely sown and late sown conditions respectively, which showed $22 \%$ reduction. While, grain yield/plant in heat susceptible parent was $15.21 \pm 0.01$ and $7.34 \pm 0.01$ during timely and late sown condition, respectively and percent reduction in yield was $51.75 \%$. Similar trends were observed in other yield components like spikelets/spike, grain number/spike, grain weight/spike and 100 grains weight as

Table 1: Mean of parents and recombinant inbred lines (RILs) and range of RILs for morphological traits in timely sown and late sown conditions in two years

\begin{tabular}{|c|c|c|c|c|c|c|c|c|}
\hline \multirow[t]{2}{*}{ Traits } & \multicolumn{2}{|c|}{ WH1021 } & \multicolumn{2}{|c|}{ WH711 } & \multicolumn{2}{|c|}{ RILs mean } & \multicolumn{2}{|c|}{ RILs range } \\
\hline & Timely & Late & Timely & Late & Timely & Late & Timely & Late \\
\hline \multicolumn{9}{|l|}{ 2015-16 } \\
\hline $\mathrm{PH} 70$ & $57.5 \pm 0.2$ & $43.7 \pm 0.2$ & $43.9 \pm 0.2$ & $28.8 \pm 0.2$ & $50.1 \pm 1.1$ & $35.9 \pm 0.9$ & $30.0-66.3$ & $16.7-45.3$ \\
\hline PH 100 & $98.9 \pm 0.4$ & $70.6 \pm 0.2$ & $82.6 \pm 0.5$ & $65.9 \pm 0.3$ & $89.9 \pm 1.2$ & $65.6 \pm 0.8$ & $67.0-119.3$ & $45.3-78.3$ \\
\hline $\mathrm{DH}$ & $87.6 \pm 0.3$ & $78.6 \pm 0.4$ & $93.4 \pm 0.2$ & $85.1 \pm 0.3$ & $92.9 \pm 1.3$ & $82.0 \pm 1.31$ & $86.7-100.2$ & $75.4-93.0$ \\
\hline DM & $134.5 \pm 0.6$ & $114.7 \pm 0.2$ & $140 \pm 0.9$ & $117.3 \pm 0.2$ & $135.3 \pm 0.2$ & $117.2 \pm 0.9$ & $127.2-141.6$ & $111.6-122.7$ \\
\hline SL & $13.4 \pm 1.0$ & $11.3 \pm 0.6$ & $12.8 \pm 0.5$ & $10.5 \pm 0.6$ & $13.1 \pm 0.3$ & $11.3 \pm 0.1$ & $10.9-15.9$ & $9.3-13.5$ \\
\hline SNS & $19.8 \pm 0.1$ & $18.1 \pm 0.3$ & $21.1 \pm 0.2$ & $17.6 \pm 0.4$ & $20.1 \pm 0.1$ & $17.9 \pm 0.3$ & $14.5-23.4$ & $12.9-22.0$ \\
\hline GNS & $66.4 \pm 0.3$ & $56.1 \pm 0.5$ & $56.7 \pm 0.4$ & $48.1 \pm 0.5$ & $68.5 \pm 1.9$ & $55.1 \pm 1.36$ & $42.0-91.0$ & $30.3-74.3$ \\
\hline GWS & $2.39 \pm 0.06$ & $1.97 \pm 0.05$ & $2.57 \pm 0.04$ & $1.78 \pm 0.03$ & $2.51 \pm 0.18$ & $1.73 \pm 0.16$ & $1.05-3.98$ & $0.46-2.95$ \\
\hline BY & $26.82 \pm 0.03$ & $21.34 \pm 0.19$ & $33.30 \pm 0.04$ & $15.14 \pm 0.13$ & $27.40 \pm 0.42$ & $16.40 \pm 0.24$ & $12.00-44.76$ & $7.40-27.60$ \\
\hline $100 \mathrm{GW}$ & $3.68 \pm 0.08$ & $3.18 \pm 0.04$ & $4.48 \pm 0.01$ & $3.18 \pm 0.04$ & $3.68 \pm 0.18$ & $2.69 \pm 0.04$ & $2.09-4.96$ & $1.72-3.57$ \\
\hline $\begin{array}{l}\text { GY } \\
2016-17\end{array}$ & $11.36 \pm 0.04$ & $8.90 \pm 0.02$ & $15.21 \pm 0.01$ & $7.34 \pm 0.01$ & $13.50 \pm 0.12$ & $7.82 \pm 0.10$ & $6.59-17.45$ & $3.77-11.25$ \\
\hline $\mathrm{PH} 70$ & $54.2 \pm 0.2$ & $35.0 \pm 1.5$ & $44.7 \pm 0.1$ & $26.8 \pm 0.2$ & $47.8 \pm 0.7$ & $34.7 \pm 0.4$ & $20.8-65.8$ & $11.8-49.3$ \\
\hline PH 100 & $101.3 \pm 0.7$ & $67.7 \pm 0.4$ & $83.8 \pm 0.3$ & $66.4 \pm 0.6$ & $92.4 \pm 1.4$ & $59.3 \pm 0.9$ & $73.3-125.1$ & $40.9-77.2$ \\
\hline $\mathrm{DH}$ & $86.3 \pm 0.3$ & $80.0 \pm 0.3$ & $92.8 \pm 0.3$ & $84.0 \pm 0.4$ & $87.6 \pm 0.8$ & $80.7 \pm 0.6$ & $81.7-107.0$ & $72.3-94.3$ \\
\hline DM & $135.3 \pm 0.7$ & $114.0 \pm 0.3$ & $140.6 \pm 0.3$ & $116.4 \pm 0.3$ & $138.3 \pm 1.2$ & $115.2 \pm 0.9$ & $130.9-145.8$ & $119.6-120.7$ \\
\hline SL & $13.8 \pm 0.1$ & $11.5 \pm 0.2$ & $12.7 \pm 0.3$ & $10.7 \pm 0.1$ & $13.2 \pm 0.4$ & $11.3 \pm 0.3$ & $10.4-15.9$ & $9.1-13.6$ \\
\hline SNS & $21.5 \pm 0.4$ & $19.6 \pm 0.2$ & $20.8 \pm 0.3$ & $18.1 \pm 0.5$ & $22.4 \pm 0.6$ & $20.1 \pm 0.6$ & $18.3-24.7$ & $15.3-22.0$ \\
\hline GNS & $64.0 \pm 0.5$ & $56.9 \pm 0.2$ & $59.7 \pm 0.7$ & $49.2 \pm 0.1$ & $67.5 \pm 0.9$ & $56.3 \pm 0.9$ & $44.6-94.0$ & $34.3-78.7$ \\
\hline GWS & $2.48 \pm 0.01$ & $1.93 \pm 0.01$ & $2.57 \pm 0.03$ & $1.62 \pm 0.01$ & $2.72 \pm 0.04$ & $1.76 \pm 0.03$ & $0.93-4.38$ & $0.68-3.03$ \\
\hline BY & $27.83 \pm 0.44$ & $21.25 \pm 0.38$ & $32.87 \pm 0.61$ & $14.93 \pm 0.18$ & $25.60 \pm 0.42$ & $14.90 \pm 0.25$ & $10.20-42.96$ & $5.90-26.10$ \\
\hline $100 \mathrm{GW}$ & $3.86 \pm 0.01$ & $3.03 \pm 0.02$ & $4.32 \pm 0.07$ & $3.32 \pm 0.02$ & $4.00 \pm 0.06$ & $3.13 \pm 0.07$ & $1.79-6.84$ & $1.16-4.89$ \\
\hline GY & $11.81 \pm 0.32$ & $9.25 \pm 0.05$ & $13.66 \pm 0.73$ & $7.74 \pm 0.20$ & $14.25 \pm 0.23$ & $8.28 \pm 0.13$ & $5.60-21.00$ & $2.66-15.57$ \\
\hline
\end{tabular}

Values are mean $\pm \mathrm{SE}, \mathrm{PH} 70$ - plant height at 70 days after showing (cm); $\mathrm{PH} 100$ - plant height at 100 days after showing (cm); DH-days to heading; DMDays to maturity; SL- Spike length (cm); SNS- number of spikelets/spike; GNS- number of grains/spike; GWS- grains weight/spike (g); BY- biological yield/plant (g); $100 \mathrm{GW}$ - 100 grain weight (g); GY-grain yield/plant (g) 
Table 2: Mean of parents and recombinant inbred lines (RILs) and range of RILs for physiological traits in timely sown and late sown conditions in two years

\begin{tabular}{|c|c|c|c|c|c|c|c|c|}
\hline \multirow{2}{*}{$\begin{array}{l}\text { Physiological } \\
\text { traits }\end{array}$} & \multicolumn{2}{|c|}{ WH1021 } & \multicolumn{2}{|c|}{ WH711 } & \multicolumn{2}{|c|}{ RILs mean } & \multicolumn{2}{|c|}{ RILs range } \\
\hline & Timely & Late & Timely & Late & Timely & Late & Timely & Late \\
\hline $\mathrm{NDVI}$ at $10 \mathrm{DAA}$ & $0.71 \pm 0.02$ & $0.65 \pm 0.01$ & $0.66 \pm 0.03$ & $0.59 \pm 0.01$ & $0.67 \pm 0.02$ & $0.59 \pm 0.01$ & $0.56-78$ & $0.43-69$ \\
\hline Pn at 10DAA & $14.07 \pm 0.05$ & $11.66 \pm 0.06$ & $13.82 \pm 0.10$ & $6.62 \pm 0.05$ & $13.08 \pm 0.18$ & $9.52 \pm 0.87$ & $7.97-18.61$ & $5.30-14.05$ \\
\hline$E$ at anthesis & $4.9 \pm 0.29$ & $4.43 \pm 0.12$ & $5.25 \pm 0.16$ & $4.55 \pm 0.11$ & $5.39 \pm 0.10$ & $4.03 \pm 0.06$ & $3.82-6.82$ & $2.33-6.36$ \\
\hline iWUE at anthesis & $83.43 \pm 1.10$ & $102.6 \pm 0.58$ & $74.63 \pm 0.84$ & $89.67 \pm 4.40$ & $74.57 \pm 1.328$ & $71.43 \pm 5.716$ & $44.15-113.29$ & $38.72-109.31$ \\
\hline iWUE at 10 DAA & $84.26 \pm 1.12$ & $97.15 \pm 0.83$ & $75.56 \pm 2.96$ & $80.98 \pm 0.39$ & $65.18 \pm 1.47$ & $67.33 \pm 6.66$ & $30.74-114.63$ & $38.41-109.58$ \\
\hline $\mathrm{NDVI}$ at $10 \mathrm{DAA}$ & $0.70 \pm 0.02$ & $0.68 \pm 0.01$ & $0.63 \pm 0.02$ & $0.55 \pm 0.03$ & $0.66 \pm 0.02$ & $0.60 \pm 0.01$ & $0.53-0.79$ & $0.45-0.73$ \\
\hline Pn at 10DAA & $13.88 \pm 0.47$ & $12.37 \pm 0.3$ & $13.75 \pm 0.65$ & $9.56 \pm 0.19$ & $13.08 \pm 0.76$ & $9.47 \pm 1.16$ & $6.61-18.61$ & $5.30-15.04$ \\
\hline$E$ at anthesis & $6.68 \pm 0.13$ & $5.97 \pm 0.12$ & $5.12 \pm 0.26$ & $4.57 \pm 0.12$ & $5.54 \pm 0.22$ & $4.34 \pm 0.19$ & $3.96-6.96$ & $2.64-6.67$ \\
\hline iWUE at anthesis & $91.27 \pm 1.69$ & $115.02 \pm 2.14$ & $93.23 \pm 1.02$ & $113.12 \pm 1.34$ & $77.01 \pm 4.91$ & $74.58 \pm 4.716$ & $47.29-121.29$ & $50.79-126.40$ \\
\hline iWUE at 10 DAA & $73.31 \pm 2.71$ & $86.93 \pm 2.54$ & $61.06 \pm 2.12$ & $69.65 \pm 2.02$ & $60.07 \pm 4.3$ & $60.08 \pm 5.15$ & $29.34-102.16$ & $43.48-86.93$ \\
\hline
\end{tabular}

Values are mean $\pm S . E$.; DAA-Days after anthesis; $P_{n}$-Photosynthetic rate; $E-$ Transpiration rate; iWUE- intrinsic water use efficiency

shown in Table 1. Plant height at 70 and 100 days after sowing ranged from $30.0-66.3 \mathrm{~cm}$ and $67.0-119.3 \mathrm{~cm}$ during timely sown and $16.7-45.3 \mathrm{~cm}$ and $45.3-78.3 \mathrm{~cm}$ during late sown, respectively. Days to heading reported during timely sown ranged from 81.7-107.0 and 72.3-94.3 during late sown. Days to maturity ranged between 130.9-145.8 and 119.6-120.7 during timely sown and late sown, respectively. NDVI observed 10 days after anthesis was 0.71 and 0.65 in WH1021, while 0.66 and 0.59 in WH711 under timely and late sown conditions, respectively (Table 2). Photosynthetic rate of flag leaf recorded 10 days after anthesis ranged between 7.97-18.61 $\mu \mathrm{mol} \mathrm{CO} \mathrm{m}^{-2} \mathrm{~s}^{-1}$ during timely sown while 5.30-14.056 $\mu \mathrm{mol} \mathrm{CO} \mathrm{m}^{-2} \mathrm{~s}^{-1}$ during late sown. Range of transpiration rate reported at anthesis was 3.82-6.82 and 2.33$6.36 \mathrm{mmol} \mathrm{H} \mathrm{O} \mathrm{m}^{-2} \mathrm{~s}^{-1}$ during timely and late sown conditions, respectively. Intrinsic water use efficiency at anthesis calculated from photosynthetic rate by stomatal conductance during timely sown and late sown was 91.27 and $115.02 \mu \mathrm{mol} \mathrm{CO}_{2} \mathrm{~mol}^{-1} \mathrm{H}_{2} \mathrm{O}$ in WH1021 while, 93.23 and $113.12 \mu \mathrm{mol} \mathrm{CO}_{2} \mathrm{~mol}^{-1} \mathrm{H}_{2} \mathrm{O}$ in WH711, respectively. Range of intrinsic water use efficiency 10 days after anthesis was 29.34-102.16 and 43.48-86.93 $\mu_{\mathrm{mol} \mathrm{CO}} \mathrm{mol}^{-1} \mathrm{H}_{2} \mathrm{O}$.

SSR polymorphism and formation of linkage map: Hundred simple sequence repeats (SSRs) primers were used to detect polymorphism between parental genotypes of wheat, WH1021 (heat tolerant) and WH711 (heat susceptible), out of which 22 SSRs (22\%) were found polymorphic. By using these 22 SSRs, 11 linkage groups of $\mathrm{WH} 1021 \times \mathrm{WH} 711$ population were constructed. The maximum numbers of markers reported in " $\mathrm{A}$ " genome followed by $\mathrm{D}$ and $\mathrm{B}$ genome of wheat.

QTL analysis: Composite interval mapping (CIM) analysis by WinQTL Cartographer 2.5 revealed fourteen QTLs for seven

Table 3: Effect of Quantitative trait loci (QTL) in WH1021 (heat tolerant) $\times$ WH711 (heat susceptible) recombinant inbred lines (RILs) reported by composite interval mapping (CIM) using QTL Cartographer

\begin{tabular}{|c|c|c|c|c|c|c|c|}
\hline Trait & QTL & Marker interval & Interval (cM) & Chromosome & LOD & R2 & Trial \\
\hline \multirow[t]{2}{*}{ Plant height } & Qph.ccshau-2A & xgwm512-xgwm448 & 35.3 & $2 A$ & 2.1 & 17.74 & LS 16-17 \\
\hline & Qph.ccshau-4A & xgwm165-xcfd71 & 25.1 & $4 \mathrm{~A}$ & 3.2 & 33.37 & LS 15-16 \\
\hline \multirow[t]{2}{*}{ Days to heading } & Qdh.ccshau-2A & xgwm512-xgwm448 & 35.3 & $2 \mathrm{~A}$ & 2.7 & 6.11 & LS 16-17 \\
\hline & Qdh.ccshau-2D & barc124-xgwm102 & 27.9 & $2 \mathrm{D}$ & 4.2 & 0.74 & LS 16-17 \\
\hline \multirow[t]{3}{*}{ Days to maturity } & Qdm.ccshau-2.1D & barc124-xgwm102 & 27.9 & $2 D$ & 3.4 & 1.46 & TS 16-17 \\
\hline & Qdm.ccshau-2.2D & gwm249-gwm382 & 25.6 & $2 \mathrm{D}$ & 2.74 & 8.4 & LS 16-17 \\
\hline & Qiwu.ccshau-2.1A & xgwm497-xgwm512 & 5.2 & $2 \mathrm{~A}$ & 2.7 & 0.53 & TS $15-16$ \\
\hline \multirow[t]{3}{*}{ iWUE } & Qiwu.ccshau-2.2A & xgwm512-xgwm448 & 35.3 & $2 \mathrm{~A}$ & 3.6 & 38.92 & TS 15-16 \\
\hline & Qiwu.ccshau-4A & xgwm165-xcfd71 & 25.1 & $4 \mathrm{~A}$ & 3.7 & 0.68 & TS $15-16$ \\
\hline & Qiwu.ccshau-2.3A & xgwm512-xgwm448 & 35.3 & $2 \mathrm{~A}$ & 10 & 48.00 & LS $15-16$ \\
\hline \multirow[t]{2}{*}{ Photosynthetic rate $(\mathrm{Pn})$} & Qpn.ccshau-2.1D & barc124-xgwm102 & 27.9 & $2 \mathrm{D}$ & 3.6 & 78.13 & TS $15-16$ \\
\hline & Qpn.ccshau-2.2D & barc124- xgwm102 & 27.9 & $2 D$ & 3.4 & 5.01 & TS $16-17$ \\
\hline Transpiration rate $(\mathrm{E})$ & Qe.ccshau-4A & xgwm165-xcfd71 & 25.1 & $4 \mathrm{~A}$ & 3.6 & 6.25 & TS 16-17 \\
\hline NDVI & Qndvi.ccshau-5A & barc186-barc141 & 28.8 & $5 A$ & 2.2 & 8.26 & LS $15-16$ \\
\hline
\end{tabular}

$\mathrm{R}^{2}$ percentage of phenotypic variance showed by $\mathrm{QTL}$; LOD- likelihood of odd ratio 
agronomical and physiological traits (Table 3). Result of QTL analysis for seven traits reported on six regions of chromosomes by using CIM, shown in Fig. 1, 2 and 3. The LOD value of identified QTLs ranged from 2.1 (QPh70.ccshau-2A) to 10 (Qlwue.ccshau$2 \mathrm{~A})$ explaining 17.74 and $48.00 \%$ phenotypic variation.

Two QTLs of plant height in wheat were mapped on chromosome 2A (Qph.ccshau-2A at map position $35.3 \mathrm{cM}$ ) and chromosome 4A (Qph.ccshau-4A at map position $25.1 \mathrm{cM}$ ) revealing 17.74 and $33.37 \%$ phenotypic variation. Two QTLs associated with days to heading were mapped on chromosomes 2A (Qdh.ccshau-2A at map position 35.3) and 2D (Qdh.ccshau$2 \mathrm{D}$ at map position 27.9 ) with LOD value of 2.7 and 4.2 ; and 6.11 and $0.74 \%$ phenotypic variation, respectively. Composite interval mapping revealed two QTLs for days to maturity on chromosome 2D at map positions 27.9 and $25.6 \mathrm{cM}$ had the 3.4 and 2.74 LOD values, respectively. Out of four QTLs associated with intrinsic water use efficiency, three were mapped on chromosomes $2 \mathrm{~A}$ (LOD values of 2.7, 3.6 and 10) and one on chromosome $4 A$ (LOD value of 3.7). QTLs (Qiwu.ccshau-2.2A and Qiwu.ccshau-2.3A) flanked by markers Xgwm512-Xgwm448 showed consistency and explained significant phenotypic variation (38.92 and $48.00 \%$ ) over two environments i.e. timely and late sown for intrinsic water use efficiency. Two QTLs revealed form analysis by CIM for photosynthetic rate were Qpn.ccshau-2.1D and Qpn.ccshau-2.2D having map position of 27.9 and was consistent over two years 2015-16 and 2016-17 of timely sown environment. Out of two QTLs present on chromosome 4A flanked by markers Xgwm165-Xcfd71, one QTL (Qe.ccshau$4 \mathrm{~A})$ was associated with transpiration rate and other (Qph.ccshau-4A) was associated with plant height showed 6.25 and $33.37 \%$ phenotypic variation. QTL (Qndvi.ccshau-5A mapped at $28.8 \mathrm{cM}$ ) for NDVI reported on chromosome $5 \mathrm{~A}$ had flanking markers barc186-barc141 with phenotypic variance of $8.26 \%$. Chromosome 2D had consistent QTL for photosynthetic rate over two years, days to maturity and days to heading and flanked by markers barc124-Xgwm102 (27.9 cM).

In the present study, experiments were conducted to evaluate WH1021 × WH711 derived RILs population for various morphological and physiological traits during rabi seasons of 2015-16 and 2016-17 under two environments i.e. timely and late sown at CCS Haryana Agricultural University, Hisar. A DNA fingerprint database of RILs plants prepared by using polymorphic SSR markers distributed on wheat genome was used to identify QTLs for morphological and physiological traits using WinQTL cartographer 2.5. It is evident from the various morphological and physiological data under both environments, that the performance of parents and their RILs population was better under timely sown as compared to late sown environment, and also revealed from the study that the WH1021 (heat tolerant parent) performs better under high temperature than WH711 (heat susceptible parent) during both the years. Hakim et al. (2012) and Bala et al. (2014) also reported similar results in their studies on these traits under late sown conditions.

The optimum temperature for wheat at anthesis and grain filling ranged from 12 to $22^{\circ} \mathrm{C}$ and temperature above this causes drastic reduction in wheat yield (Farooq et al., 2011). Wardlaw et al. (1989) also observed 3 to $4 \%$ reduction in yield with every $1^{\circ} \mathrm{C}$ rise in temperature. High temperature affects both vegetative as well as reproductive stages of plant but its drastic effect was more
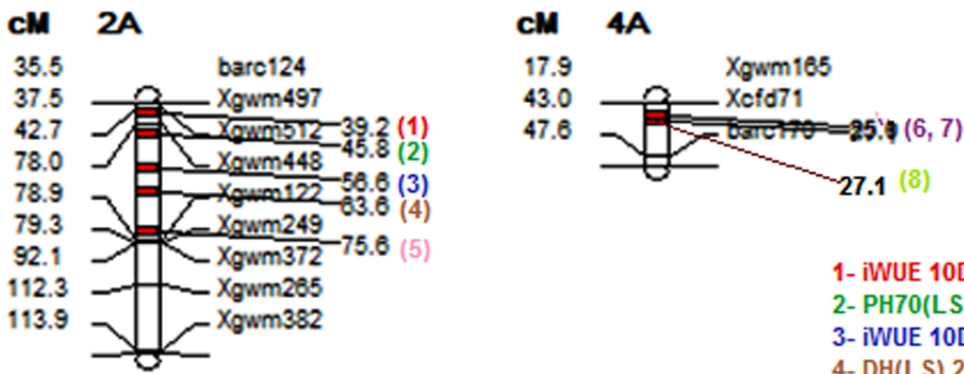

1- iWUE 10DAA(TS) 2015-16

2- $\mathrm{PH70}$ (LS) 2016-17

3- iWUE 10DAA(TS) 2015-16

4- DH(LS) 2016-17

5- iWUE anth(LS) 2015-16

6- E anth(TS) 2016-17

7- PH70 (LS) 2015-16

8- iWUE 10DAA(TS) 2015-16

9- An 10DAA (TS) 2015-16

10- An 10DAA(TS) 2016-17

11- DH(LS) 2016-17

12- DM(TS) 2016-17

13- DM(LS) 2016-17

14- NDVI 10DAA(LS) 2015-16

Fig.1 : Chromosomal locations of quantitative trait loci (QTLS) for various physiological and morphological traits identified in RILs derived from WH1021×WH711. 


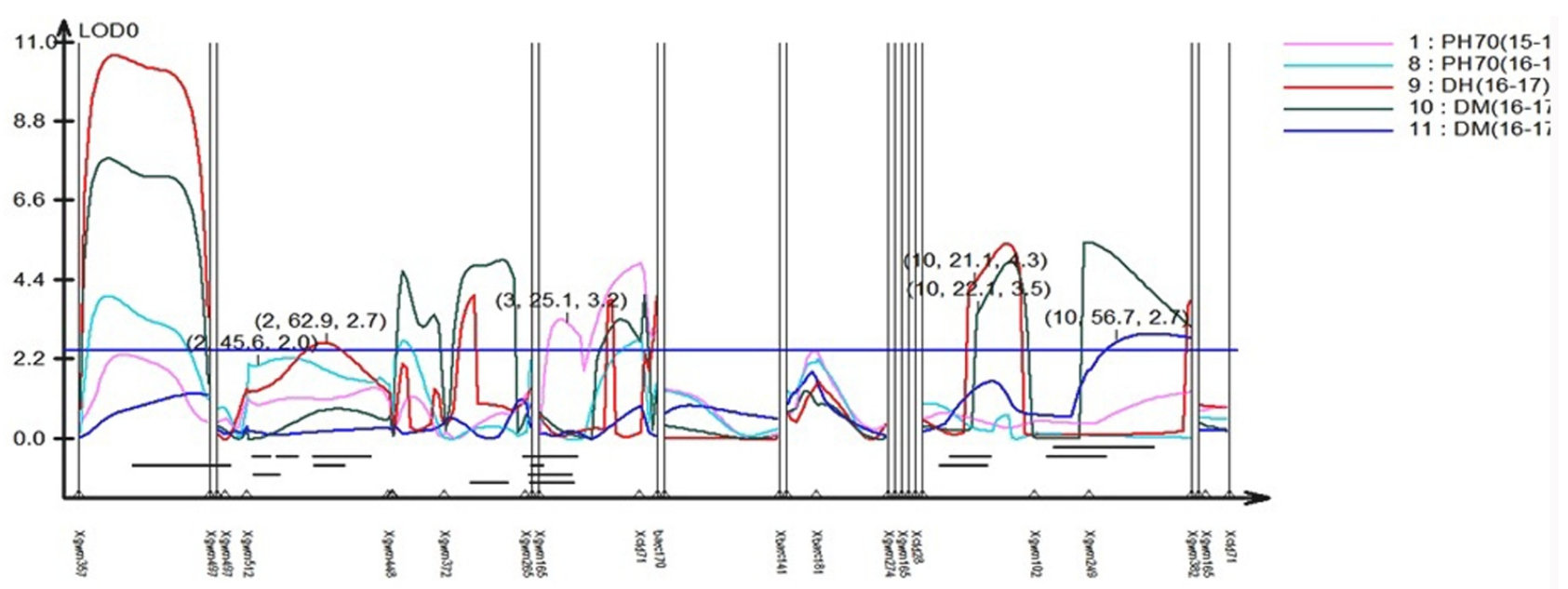

Fig. 2: Graphic display of seven wheat chromosomes of detected QTLs for morphological traits.

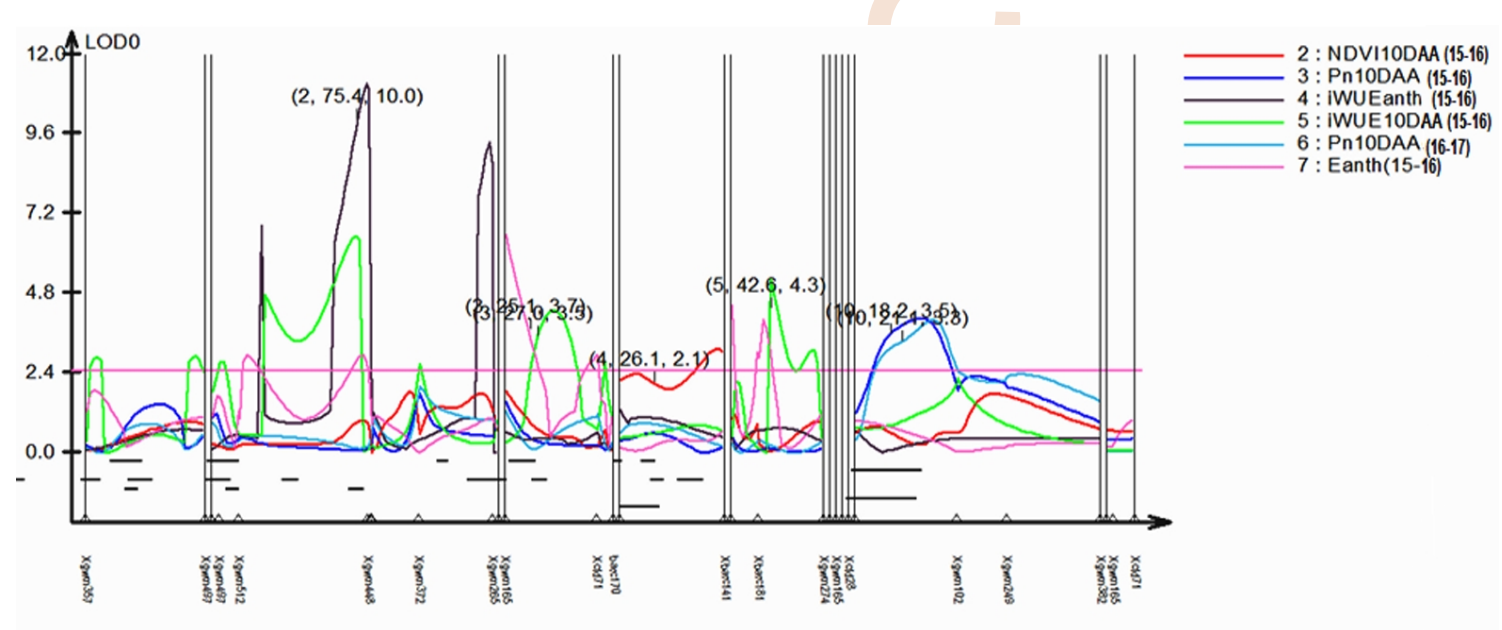

Fig. 3 : Graphic display of seven wheat chromosomes of detected QTLs for physiological traits.

on reproductive stage (Reynolds et al., 1994; Munjal and Rana 2003; Sunita et al., 2017). This variability among the RILs population was found which make them good source for selecting superior and desired genotypes for further improvement. Many early workers including Huang et al. (2003); Farooq et al. (2011) and Mohammadi et al. (2012) reported high variability for different traits in wheat. Significant variation for environment and genotype for grain yield and days to heading reported differential responses of genotypes over the normal and heat stressed conditions (Saadalla, 1997; Zahra et al., 2015). The results showed reduction in days to heading and days to maturity in late sown over timely sown but greater reduction was observed in heat sensitive parent WH711 as compared to heat tolerant parent WH1021. Jena et al. (2017) observed acceleration in heading and maturity during high temperature condition, which was also reported in this study. Nahar et al. (2010) and Saxena et al. (2016) also observed reduction in maturity period of wheat genotypes due to the effect of heat stress, showed similarity with the results of present study.

The temperature variation of timely and late sown conditions in the present investigation was significant to induce heat stress caused reduction in all the traits studied. However, susceptibility of crop to heat stress depends on the genotype, developmental stage, intensity of temperature and duration of exposure (Nahar et al. 2010; Faroog et al., 2011). The response of parents and RILs population to heat stress differentiate with the trait in terms of reduction. In present study, heat susceptible 
parent WH711 suffered higher reduction in photosynthetic rate $(\mathrm{Pn})$, stomatal conductance (gs), chlorophyll content $(\mathrm{CHC})$, normalized difference vegetation index (NDVI) at anthesis and 10 days after anthesis than heat tolerant WH1021 under late sown conditions over both the crop seasons. High-temperature stress causes photosynthesis reduction through disruptions in the structure and function of chloroplasts and reductions in chlorophyll content in wheat leaves (Brestic et al., 2016). These changes lead to a significant decrease in the carbon assimilation capacity in wheat plants. In the present study heat stress at 10 DAA caused significant decrease in photosynthetic rate. Increase in temperature from 22 to $32^{\circ} \mathrm{C}$ resulted in decline of photosynthetic rate and transpiration (Zhang et al., 2010). Photosynthesis is most susceptible trait to high temperature (Wahid et al., 2007) and decline in photosynthesis reduced growth and grain yield of wheat (Al-Khatib and Paulsen, 1990). Singh et al. (2017) observed decrease in photosynthetic rates rapidly during grain filling period. Significant reduction was reported in chlorophyll content, efficiency of PS-II, photosynthetic rate $(\mathrm{Pn})$, transpiration rate $(\mathrm{E})$, stomatal conductance $(\mathrm{gs})$ and intrinsic water use efficiency (iWUE) (Harding et al., 1990; Sunita and Munjal, 2017). Transpiration rate is an important index of physiological attributes strongly affected by climatic variations.

In the present investigation, transpiration rate increased significantly at 10 DAA under late sown conditions. Gupta et al. (2015) reported highest rate of transpiration in tolerant genotypes, which showed similar trends with the results of this attribute in the present study, as heat tolerant parent WH1021 has high rate of transpiration during late sown than heat sensitive parent WH711. It was inferred that enhanced transpiration might help tolerant genotype to maintain higher rate of photosynthesis through cooling effect under heat stress. Previous studies on plant WUE showed that WUE determinations rely on direct measurement of instantaneous gas exchange rates (photosynthesis and stomatal conductance) at the leaf level with portable equipment.

QTL associated with morphological and physiological traits: QTL mapping offers important information on the number and location of the loci which control quantitative traits and the information provided is useful for MAS method (Kato et al., 2000; Liu, 1998). It has been proved that heat tolerance is quantitatively inherited and continuously distributed (Blum, 1988; Yang et al., 2002), so, a number of traits are responsible for heat stress tolerance. Two QTLs mapped for plant height were on chromosomes $2 \mathrm{~A}$ (map position $35.3 \mathrm{cM}$ ) and $4 \mathrm{~A}$ (map position $25.1 \mathrm{cM}$ ). Earlier, QTLs for plant height were also identified on chromosomes 1D, 2D, 3D, 4B and 4D (Wang et al., 2007; Mason et al., 2013). Two QTLs for days to heading were mapped, one on chromosomes 2A (map position $35.3 \mathrm{cM}$ ) and other on 2D (map position $27.9 \mathrm{cM}$ ). Present study is consistent with the previous studies of QTLs reported for days to heading (ear emergence time), on chromosomes 1A, 2B, 2D, 4B, 5A, 5B, 7A, 7B \& 7D (Bennett et al., 2012; Mason et al., 2013). QTLs for heading time, affect the yield under stress conditions because the duration of lifecycle influence the time and intensity of stress accomplished by the plants (Shindo et al., 2003; Reynolds and Tuberso, 2008). Photoperiodism responsive gene (php) and vernalization (vrn) are major genetic factors controlling heading time in wheat (Kato et al., 1999). QTLs for days to maturity were identified on chromosome 2D, which were also reported previously (Cuthbert et al., 2008; Wang et al., 2009; Mason et al., 2013). In present study, QTLs for intrinsic water use efficiency were mapped on chromosome $2 A$ and $4 A$ and single QTL for transpiration rate was mapped on 4A chromosome. Tricker et al. (2018) reported that water deficits and high temperatures frequently occur simultaneously at sensitive growth stages, reducing wheat yields, so, there should be a fine control of water relations across the growing cycle and that might be achieved through fine management of spatial and temporal gas exchange.

QTL for photosynthetic rate was mapped on chromosome 2D at map position $27.9 \mathrm{cM}$, which was consistent for both years 2015-16 and 2016-17. Single QTL for NDVI was mapped on chromosome $5 \mathrm{~A}$ which was also reported earlier by Pinto et al. (2010). QTLs for NDVI were also reported previously on other genomic regions of chromosomes 1B, 2A, 2B, 3B, 4A, 6A and 7B (Pinto et al., 2010; Graziani et al., 2014). Xu et al. (2017) studied a set of 131 recombinant inbred lines of wheat under different water regimes, across two years to map quantitative trait loci (QTLs) for yield and photosynthetic traits. They found that the four photosynthetic traits (chlorophyll content, leaf water use efficiency, net photosynthetic rate and intercellular $\mathrm{CO}_{2}$ concentration) were co-located with grain yield and/or yield components on various Meta-QTLs.

Acuna-Galindo et al. (2015) used 854 individual reported QTLs; 502 associated with drought stress, 234 with heat stress and 118 linked to physiological traits in nonstressed environments for 81 different traits across a range of environments including both field and controlled experiments to analyze Meta QTL. The results revealed that individual QTL clustered into $66 \mathrm{MQTL}$ regions distributed throughout the genome, 43 MQTL co-localized for drought and heat stress, 20 specific for drought stress, 2 specific for heat stress, and 1 MQTL specific for physiological traits in non-stressed environments. Ali et al. (2013) found a QTL on 1B to be linked with heat tolerance. Sadat et al. (2013) validated the previously reported 14 SSR markers linked with QTLs for heat tolerance in the studies of Yang et al. (2002), Mohammadi et al. (2008) and Mason et al. (2010). The results demonstrated multiple QTLs control heat tolerance of common wheat and reported QTLS that warrant further study for heat tolerance breeding and are helpful for understanding the genetic basis of heat stress tolerance at individual QTL level in wheat.

To conclude, the outcomes of present research study revealed the fact that heat tolerant parent $(\mathrm{WH} 1021)$ was affected to a lesser extent than heat susceptible parent (WH711) under heat stress conditions at reproductive stage. The association of phenotypic data with genotypic during QTL mapping, 14 QTLs 
were identified with significant phenotypic variation $\left(R^{2}\right)$. Among these identified QTLs, QTLs for photosynthetic rate and intrinsic water use efficiency at chromosome 2D were found consistent during both years. These QTLs can be used for improvement of heat tolerance in wheat through MBBS (marker based breeding scheme) and Marker Assisted Selection (MAS).

\section{Acknowledgment}

The authors acknowledge the financial support from Council of Scientific \& Industrial Research (CSIR), India, for this research work.

\section{References}

Acuna-Galindo, M.A., R.E. Mason, N.K. Subramanian and D.B. Hays: Meta-analysis of wheat QTL regions associated with adaptation to drought and heat stress. Crop Sci., 55, 477-492 (2015).

Al-Khatib, K. and G.M. Paulsen: Photosynthesis and productivity during high temperature stress of wheat genotypes from major world regions. Crop Sci., 30, 1127-1132 (1990).

Ali, M.B., A.M.H. Ibrahim, S. Malla, J. Rudd and D.B. Hays: Family-based QTL mapping of heat stress tolerance in primitive tetraploid wheat (Triticum turgidum L.). Euphytica, 192, 189-203 (2013).

Bala, S., B. Asthir and S.N. Bains: Effect of terminal heat stress on yield and yield attributes of wheat. Indian J. Appl. Res., 4, 1-2 (2014).

Balota, M., W.A. Payne, S.R. Evett and T.R. Peters: Morphological and physiological traits associated with canopy temperature depression in three closely related wheat lines. Crop Sci., 48, 1897-1910 (2008).

Barnabas, B., K. Jager and A. Feher: The effect of drought and heat stress on reproductive processes in cereals. Plant Cell Environ., $31,11-38(2008)$.

Bennett, D., M. Reynolds, D. Mullan, A. Izanloo, P. Langridge and T. Schnurbusch: Detection of two major grain yield QTL in bread wheat (Triticum aestivum L.) under heat, drought and high yield potential environments. Theor. Appl. Genet., 125, 1473-1485 (2012).

Blum, A.: Plant breeding for stress environments. CRC Press, Boca Raton, $\mathrm{FL}(1988)$

Brestic, M., M. Ziveak, K. Kunderlikova and S.I. Allakhverdieve: High temperature specially affects the photoprotective responses of chlorophyll-b-deficient wheat mutant lines. Photosynth. Res., 130, 251-266 (2016).

Cuthbert, J.L., D.J. Somers, A.L. Brule-Babel, P.D. Brown and G.H Crow: Molecular mapping of quantitative trait loci for yield and yield components in spring wheat (Triticum aestivum L.). Theor. Appl. Genet., 117, 595-608 (2008).

Farooq, M., H. Bramley, J.A. Palta and K.H. Siddique: Heat stress in wheat during reproductive and grain-filling phases. CRC Crit. Rev. Plant Sci., 30, 491-507 (2011).

Graziani, M., M. Maccaferri, C. Royo, F. Salvatorelli and R. Tuberosa: QTL dissection of yield components and morpho-physiological traits in a durum wheat elite population tested in contrasting thermopluviometric conditions. Crop. Pasture. Sci., 65, 80-95 (2014).

Gupta, M., V. Chawla, S.S. Dhanda, R.P. Saharan and R. Munjal: Effect of terminal heat stress on yield and yield components of bread wheat genotypes. Res. Crops, 16, 42-52 (2015).

Hakim, M.A., A. Hossain, A. Jaime, T.D. Silva, V.P. Zvolinsky and M.M. Khan: Yield, protein and starch content of twenty wheat (Triticum aestivum L.) genotypes exposed to high temperature under late sowing conditions. J. Sci. Res., 4, 477-89 (2012).

Hall, A.E.: Breeding for heat tolerance. Plant Breed. Rev., 10, 129-168 (1992).

Harding, S.A., G.A. Guikema and G.M. Paulsen: Photosynthetic decline from high temperature stress during maturation of wheat. II Interaction with source and sink processes. Plant Physiol., 92, 654-658 (1990).

Huang, X.Q., H. Coster and M.W. Ganal: Advanced backcross QTL analysis for the identification of quantitative trait loci alleles from wild relatives of wheat (Triticum aestivum L.). Theor. Appl. Genet., 106, 1379 (2003)

Jena, T., R.K. Singh and M.K. Singh: Mitigation measures for wheat production. Int. J. Agric. Sci. Res., 7, 359-376 (2017).

Joshi, A.K., B. Mishra, R. Chatrath, G. Ortiz Ferrara and R.P. Singh: Wheat improvement in India: Present status, emerging challenges and future prospects. Euphytica, 157, 431-446 (2007b).

Joshi, A.K., G. Ortiz-Ferrara, J. Crossa, G. Singh and R.C. Sharma, R. Chand and R. Parsad: Combining superior agronomic performance and terminal heat tolerance with resistance to spot blotch (Bipolaris sorokiniana) in the warm humid Gangetic Plains of South Asia. Field. Crops. Res., 103, 53-61 (2007c).

Joshi, A.K., R. Chand, B. Arun, R.P. Singh and G. Ortiz Ferrara: Breeding crops for reduced tillage management in the intensive, rice-wheat systems of South Asia. Euphytica, 153, 135-151 (2007a).

Kato, K., H. Miura and S. Sawada: QTL mapping of genes controlling ear emergence time and plant height on chromosome $5 \mathrm{~A}$ of wheat. Theor. Appl. Genet., 98, 472-477 (1999).

Kato, K., H. Miura and S. Sawada: Mapping QTLs controlling grain yield and its components on chromosome 5A of wheat. Theor. Appl. Genet., 101, 1114-1121 (2000).

Liu, B.: Statistical Genomics: Linkage, mapping and QTL analysis. CRC Press, Boca Raton, FL (1998).

Mason, E.R., D.B. Hays, S. Mondal, B.R. Basnett and A.M.H. Ibrahim: QTL for yield components and canopy temperature depression in wheat (Triticum aestivum L.) under late sown field conditions. Euphytica, 194, 243-259 (2013)

Mason, R.E., S. Mondal, F.W. Beecher, A. Pacheco, B. Jampala, A.M.H. Ibrahim and D.B. Hays: QTL associated with heat susceptibility index in wheat (Triticum aestivum L.) under short-term reproductive stage heat stress. Euphytica, 174, 423-436 (2010).

Mohammadi, M., R. Karimizadeh and M.K. Shefazeadeh: Grain yield performance of bread wheat germplasm under heat and drought field conditions. Ann. Biol. Res., 3, 3149-55 (2012).

Mohammadi, V., A.A. Zali and M.R. Bihamta: Mapping QTLs for heat tolerance in wheat. J. Agric. Sci. Tech., 10, 261-267 (2008).

Munjal, R. and R.K. Rana: Evaluation of physiological traits in wheat (Triticum aestivum L.) for terminal high temperature tolerance. In: Proceedings of the Tenth International Wheat Genetics Symposium, Classical and Molecular Breeding, Poestum, Italy, 2 , pp. 804-805 (2003).

Nahar, K., K. Ahmad and M. Fujita: Phenological variation and its relation with yield in several wheat (Triticum aestivum L.) cultivars under normal and late sowing mediated heat stress conditions. Notulae. Scientia. Biologicae, 2, 51-56 (2010).

Ortiz, R., K.D. Sayre, B. Govaerts, R. Gupta and G.V. Subbarao, T. Ban, D. Hodson, J.M. Dixon, J.I. Ortiz-Monasterio and M. Reynolds: Climate change: Can wheat beat the heat? Agric. Ecosyst. Environ., 126, 46-58 (2008).

Pinto, R.S., M.P. Reynolds, C.L. Mclntyre, J.J. Olivares-Villegas and S.C. Chapman: Heat and drought QTL in a wheat population designed to minimize confounding agronomic effects. Theor. Appl. Genet., 121, 1001-1021 (2010)

Ram, K., R. Munjal, Sunita and N. Kumar: Combine effects of drought 
and high temperature on water relation traits in wheat genotypes under late and very late sown condition. Int. J. Curr. Microbiol. Appl. Sci., 6, 567-576 (2017).

Rane, J., R.K. Pannu, V.S. Sohu, R.S. Saini and B. Mishra, J. Shoran, J Crossa, M. Vargas and A.K. Joshi: Performance of yield and stability of advanced wheat genotypes under heat stressed environments of Indo-Gangetic Plains. Crop Sci., 47, 1561-1573 (2007).

Reynolds, M. and R. Tuberosa: Translational research impacting on crop productivity in drought-prone environments. Curr. Opin. Plant Biol., 11, 171-179 (2008).

Reynolds, M.P., C. Saint Pierre, A.S.I. Saad, M. Vargas and A.G. Condon: Evaluating potential genetic gains in wheat associated with stress-adaptive trait expression in elite genetic resources under drought and heat stress. Crop Sci., 47, 172-189 (2007).

Reynolds, M.P., J.I. Ortiz-Monasterio and A. McNab: Application of physiology in wheat breeding, CIMMYT, El Batan, Mexico (2001).

Reynolds, M.P., M. Balota, M.I.B. Delgado, J. Amani and R.A. Fischer: Physiological and morphological traits associated with spring wheat yield under hot, irrigated conditions. Aust. J. Plant. Physiol., 21, 717-730 (1994).

Saadalla, M.M.: Inheritance of cell membrane thermostability as a criterion for heat tolerance in wheat. Alexandria J. Agric. Res., 42 15-26 (1997).

Sadat, S., K.A. Saeid, M.R. Bihamta, S. Torabi, S.G.H. Salekdeh and G.A.L. Ayeneh: Marker assisted selection for heat tolerance in bread wheat. WorldAppl. Sci. J., 21, 1181-1189 (2013).

Saghai-Maroof, M.A., K.M. Soliman, R.A. Jorgensen and R.W. Allad: Ribosomal DNA spacer-length polymorphism in barley: Mendelian inheritance, chromosomal location and population dynamics, Proceedings of National Academy of Science U.S.A., 81, 8014 8019 (1984).

Saxena, A., P. Kumar, R.K. Goyal, N. Patel and P.S. Khapte:Assessment of water productivity of different cropping systems under drip irrigation in arid region of western India. Ann. Arid. Zone., 55, 101 $105(2016)$

Sheoran, O.P., D.S. Tonk, L.S. Kaushik, R.C. Hasija and R.S. Pannu: Statistical software package for agricultural research workers. Recent Advances in information theory, Statistics \& Computer Applications, Department of Mathematics Statistics, CCS HAU, Hisar. 139-143 (1998).

Shewry, P.R. and S. Hey: The contribution of wheat to human diet and health. Food Energy Secur., 4, 178-202 (2015).

Shindo, C., H. Tsujimoto and T. Sasakuma: Segregation analysis of heading traits in hexaploid wheat utilizing recombinant inbred lines. Heredity, 90, 56-63 (2003).
Shpiler, L. and A. Blum: Heat tolerance to yield and its components in different wheat cultivars. Euphytica, 51, 257-263 (1991).

Singh, H., S.N. Kumar, N. Ramawat and R.C. Harit: Response of wheat varieties to heat stress under elevated temperature environments. J. Agromet., 19, 17-22 (2017).

Sunita and R. Munjal: Variability in gas exchange attributes of wheat RILs subjected to high temperature stress. Agric. Sci. Digest, 37, 221225 (2017).

Sunita, R. Munjal, K. Ram, N. Kumar and S.S. Dhanda: Heat stress implications on yield and yield component in recombinant inbred lines of bread wheat at reproductive stage. Int. J. Pure Appl. Biosci., 5, 1001-1007 (2017).

Tricker, P.J., A. ElHabti, J. Schmidt and D. Fleury: The physiological and genetic basis of combined drought and heat tolerance in wheat. $J$. Exp. Bot., 69, 3195-3210 (2018).

Vijayalakshmi, K., A.K. Fritz, G.M. Paulsen, G. Bai, S. Pandravada and B.S. Gill: Modeling and mapping QTL for senescence-related traits in winter wheat under high temperature. Mol. Breed., 26, 163-175 (2010).

Wahid, A., S. Gelani, M. Ashraf and M.R. Foolad: Heat tolerance in plants: An overview. Environ. Exp. Bot., 61, 199-223 (2007).

Wang, J.H., W.J. Huang, C.J. Zhao, M.H. Yang and Z.J. Wang: The inversion of leaf biochemical components and grain quality indicators of winter wheat spectral reflectance. J. Remote. Sens. $7,277-284(2003)$

Wang, R.X., L. Hai, X.Y. Zhang, G.X. You, C.S. Yan and S.H. Xiao: QTL mapping for grain filling rate and yield-related traits in RILs of the Chinese winter wheat population Heshangmai $3 X$ Yu8679. Theor. Appl. Genet., 118, 313-325 (2009).

Wang, S., C.J. Basten and Z.B. Zeng: Windows QTL Cartographer 2.5, Department of Statistics, North Carolina State University, Raleigh, NC (2007).

Wardlaw, I.F., I.A. Dawson and P. Munibi: The tolerance of wheat to high temperatures during reproductive growth: II. Grain development. Aust. J. Agric. Res., 40, 15-24 (1989).

Xu, Y.F., S.S. Li, L.H. Li, F.F. Ma, X.Y. Fu, Z.L. Shi, H.X. Xu, P.T. Ma and D.G. An : QTL mapping for yield and photosynthetic related traits under different water regimes in wheat. Mol. Breed., 37, 34 (2017).

Yang, J., R.G. Sears, B.S. Gill and G.M. Paulsen: Quantitative and molecular characterization of heat tolerance in hexaploid wheat. Euphytica, 126, 275-282 (2002)

Zahra, N., N. Akmal, S. Naheed, N. Habib, S. Siddiqui and I. Raza: Trend analysis of rice area and yield In Punjab. Pak. J. Agric. Res., 28, 439-444 (2015).

Zhang, B., W. Liu, S.X. Chang and A.O. Anyia: Water deficit and high temperature affected water use efficiency and arabinoxylan concentration in spring wheat. J. Cereal Sci., 52, 263-269 (2010). 